\title{
SUBMERGED DUNES AND BREAKWATER EMBAYMENTS MAPPED USING WAVE INVERSIONS OF SHORE-MOUNTED MARINE X-BAND RADAR DATA
}

\author{
Paul S. Bell \\ National Oceanography Centre, Liverpool, United Kingdom
}

\begin{abstract}
Surveying very shallow coastal areas, particularly around coastal defences, can be a logistically difficult and time consuming process. A marine-radar based bathymetry mapping technique has been used to remotely map the embayments around a series of shore-parallel breakwaters at Sea Palling on the south east coast of England during the LEACOAST2 project. The duration of the deployment spanned over 2 years, with the aim of observing any evolution of bathymetric features over that timescale while providing a clear indication of the spatial variability of wave and current patterns contributing to such evolution. The embayments generated by the shore parallel breakwaters at that site are resolved and a field of subtidal dunes with a wavelength of the order of $200 \mathrm{~m}$ and amplitude around $1 \mathrm{~m}$ located in approximately $6-10 \mathrm{~m}$ of water were within the radar field of view and are evident in the remotely sensed bathymetry. Comparisons between bathymetric data obtained using conventional survey techniques and the radar based technique are presented together with measurements of tidal currents mapped using the same remote sensing method and compared with ADCP data during a storm event.
\end{abstract}

\section{Index Terms - Marine radar, terrain mapping, sediments}

\section{INTRODUCTION}

During a major storm surge in 1953 seven people drowned when the sea overtopped the dunes at Sea Palling in East Anglia as a result of a high spring tide of approximately $3.5 \mathrm{~m}$ coinciding with an estimated storm surge of $3.2 \mathrm{~m}$. Following that event, a sea wall was built to protect the village from further risk, but in recent years those sea defences began to be undercut by the sea, and a series of nine shore-parallel breakwaters (Figure 1.) were installed in conjunction with beach recharge in an attempt to protect the earlier defences.

These new breakwaters were designed to better retain the sand and hence continue the protection to that part of the coast, but the first four breakwaters performed better than expected at this site and the first breakwater on the northern updrift end of the structures now has a permanent tombolo linking the breakwater to the shore - something that was never intended in the original design. The subsequent set of five breakwaters installed during the second phase of construction were built to a slightly smaller size, spacing and with a lower height and have performed closer to their design specification.

Despite these efforts to protect the shoreline, beach recharge operations have been necessary every few years to maintain the beach at this vulnerable section of the coast.

In 2005 The UK Engineering and Physical Sciences Research Council (EPSRC) and Natural Environment Research Council (NERC) funded LEACOAST2, a collaborative research project to study the hydrodynamics and sediment processes around these breakwaters that followed on from the earlier LEACOAST project [1]. The aim was to improve the understanding of how such structures interact with the hydrodynamic and sedimentary environment and hence improve future design guidelines, as well as provide a field scale dataset for sediment process model development and validation.

\section{MEASUREMENTS}

Teams from the Universities of East Anglia, Plymouth and Liverpool and from the Proudman Oceanographic Laboratory (POL) (now the National Oceanography Centre, Liverpool) began work in 2006 with a wide range of equipment for monitoring waves, currents and sediment dynamics.

For the purpose of long term monitoring, an ARGUS video system was installed on a tower to study the nearshore and beach processes and an X-band marine radar on the roof of the local lifeboat station for looking over longer ranges of up to $4 \mathrm{~km}$. Surveys of the beaches and embayments were conducted at regular intervals both on foot and by boat using an RTK GPS system by the University of East Anglia team.

Intensive field measurement campaigns were conducted during March - April 2006 and October 2006 - January 2007 using a variety of in-situ frames and measurement systems for studying the hydro and sediment dynamics. 


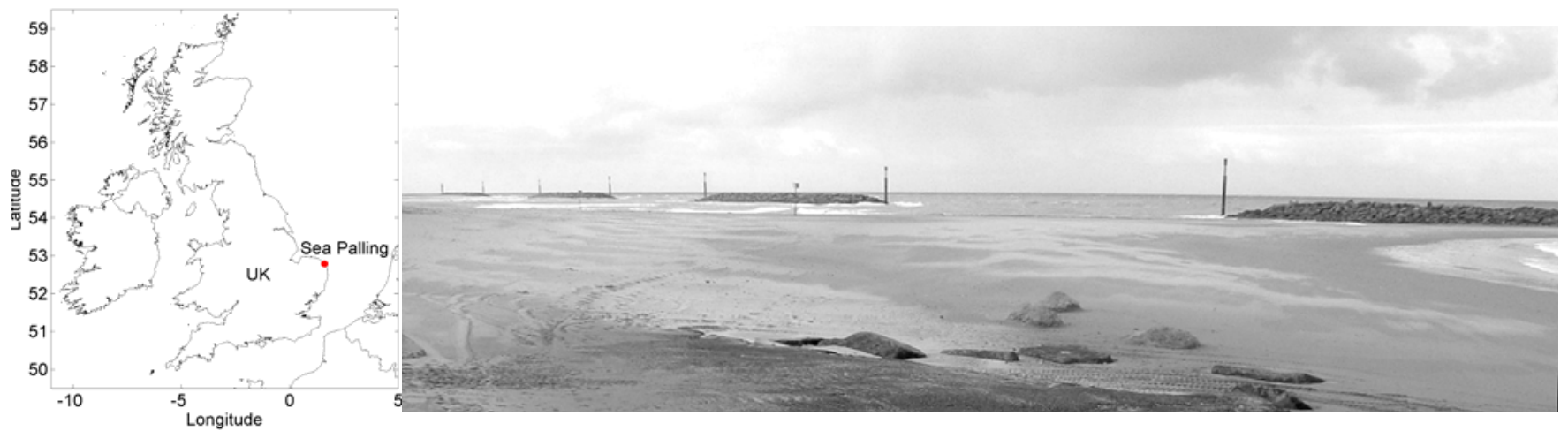

Figure 1. Location map and view of the Sea Palling breakwaters looking north from the slipway. The first phase of four breakwaters are clearly visible together with the tombolo linking to the nearest at low water. The radar was located a few metres from this position up on the flat roof of a lifeboat station.

A Kelvin Hughes marine X-band $(9.8 \mathrm{GHz})$ radar with a $2.4 \mathrm{~m}$ rotating antenna was deployed on the roof of the Sea Palling Inshore Lifeboat Station about 5m above beach level and overlooking the offshore breakwaters and associated embayments. This was coupled to a PC based digitisation system of in-house design, allowing image sequences of the sea surface to be recorded automatically every hour to ranges of $4 \mathrm{~km}$. Each individual radar record comprised a sequence of 256 images, each frame of which represents one 2.8 second rotation of the radar antenna, hence each image sequence spanned a period of around 12 minutes.

The radar signal was digitised at $20 \mathrm{MHz}$, giving radial samples at $7.5 \mathrm{~m}$ intervals, and the ping rate was of the order of $3 \mathrm{kHz}$. The antenna beam pattern was approximately 0.8 degrees in the horizontal, leading to the sample footprint at a distance of $1 \mathrm{~km}$ from the radar being an arc with a radial dimension of $7.5 \mathrm{~m}$ and a circumferential dimension of around $20 \mathrm{~m}$, going up to $80 \mathrm{~m}$ at a range of $4 \mathrm{~km}$.

The practical consequence of this is that the tangential resolution of the radar images degrades with range, precluding the ability to image shorter wavelength waves at longer ranges. However, the radial resolution does not degrade substantially with range, and at other sites it has been possible to resolve wave patterns and hence perform bathymetric inversions to a range of $7.5 \mathrm{~km}$ when looking into the direction of incoming waves.

Summary images of each record were produced and sent via a broadband link to the POL website so that the status of the system could be monitored via the internet, including radar snapshots of the sea surface and time-lapse images that show persistent sea surface roughness features very well. Waves tend to be visible on the radar images only when the wave height is larger than about $1 \mathrm{~m}$, so in contrast to more conventional surveying techniques this method of mapping is only appropriate during wave events. However, this would allow the bathymetry of an area to be monitored during storms when the largest changes might be expected.
Waves, tides and currents were monitored at various locations around the system of breakwaters and embayments using variety of in-situ instrument frames although none were located more than $500 \mathrm{~m}$ offshore. Of particular interest is the upward looking Acoustic Doppler Current Profiler (ADCP) record from a frame located just seaward of the northernmost breakwater, as it was located in an area sufficiently clear of the breakwaters to allow clear tidal signals to be observed. During this time there was a significant storm and surge event during which all deployed current meters showed that the usual tidal reversal was overpowered by the storm induced currents such that the ebb tidal current continued to flow to the south east rather than reverse to flow north west as would be more usual.

The majority of these instrument frames included pressure sensors, but none were in place for the full duration of the radar deployment, so a continuous unbroken water level record could not be constructed easily. Instead, advantage was taken of the UK National Tide Gauge Network which operates a network of 44 tide gauges around the UK, the nearest of which being Cromer, $20 \mathrm{~km}$ to the north of Sea Palling and Lowestoft $35 \mathrm{~km}$ to the south. Tidal residuals from these gauges were combined with tide predictions for Sea Palling itself to provide a continuous estimate of water level at the Sea Palling site for the full 2 year radar deployment. This estimated water level record compared favourably with the shorter records from in-situ pressure sensors and provided a consistent water level reference for the full period of the radar deployment, allowing radar derived water depths to be related to a fixed datum.

\section{ANALYSIS}

The extensive nature of the radar dataset and reliance on waves being present at any particular time for the data to be of use for bathymetry mapping has meant that attention has been focussed on specific hydrodynamic events. 


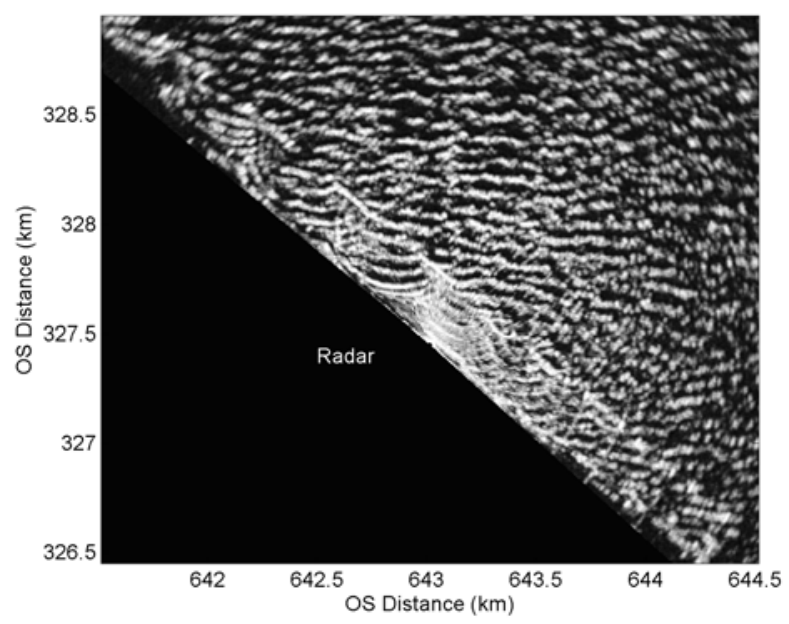

Figure 2. A snapshot of the sea surface recorded using the radar at Sea Palling during a wave event. Wave refraction into the shallow embayments between the breakwaters can clearly be seen.

In particular a storm and surge event at the end of October 2006 occurred during one of the intensive measurement campaigns when all of the in-situ frames were deployed, and on which the project partners have focussed the majority of analysis and modelling efforts.

The principle underlying the wave inversion analysis used here is that the behaviour of waves at a local scale is governed by the water depth and current. Therefore if the frequency -wavenumber spectrum, can be mapped from an imaging system such as the radar (or video) then it should be possible to infer the depth and current maps that caused the observed wave behaviour.

The wave dispersion relation used in this case approximates non-linear wave theory [2] [3] using a wave height correction to linear wave theory and has been modified to include the Doppler shift of the waves due to a mean current.

Radar data representing an area of $3 \mathrm{~km}$ x $2 \mathrm{~km}$ centred on the breakwater system was selected for detailed analysis. A snapshot of the raw radar data from this analysis area is shown in Figure 2 with brighter shading indicating stronger radar backscatter. These data were processed for bathymetry and currents using a data window of $120 \mathrm{~m}$ square and at spatial intervals of 30m [4][5][6]. Initially, four tidal cycles of hourly radar records were processed for bathymetry and currents.

\section{RESULTS - BATHYMETRY}

An example of a bathymetric map derived using the radar system is shown in Figure 3. Water depths are relative to Ordinance Datum Newlyn (ODN) - the datum used by the UK Ordinance Survey Organisation, which is approximately $0.25 \mathrm{~m}$ below mean sea level at Sea Palling.

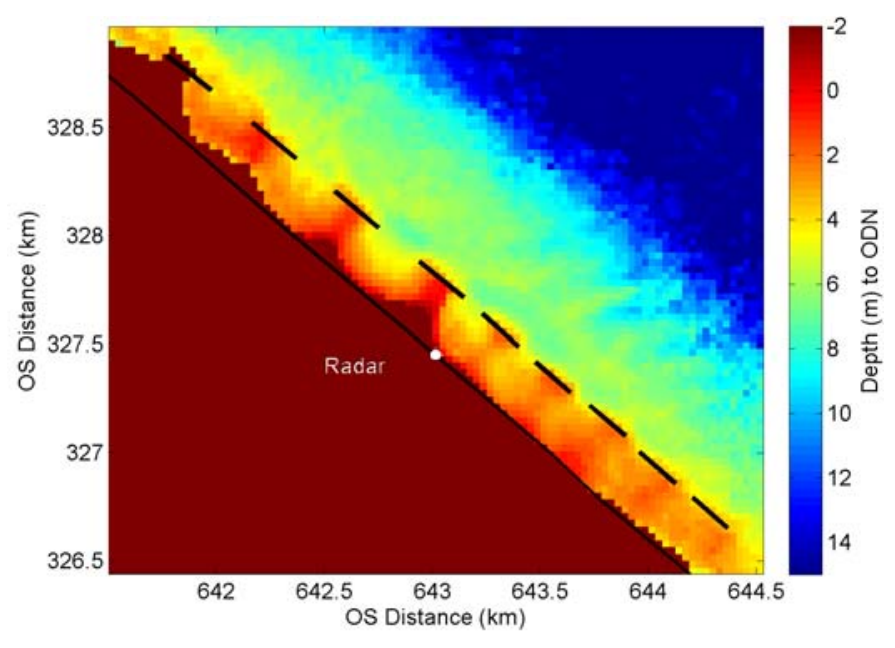

Figure 3. A radar derived bathymetric map corrected to Ordinance Datum Newlyn (ODN) using a mean tidal level. The embayments are clearly defined and a set of subtidal dunes outside the breakwaters are evident.

Transects from this radar derived bathymetric map were compared with the echo sounder survey that was conducted by the University of East Anglia team in calm conditions shortly after the wave event.

These survey lines together with the corresponding radar derived bathymetry transects are shown in Figure 4. The plots illustrate that while there are differences between the survey and the radar derived depths, generally of less than a metre, the variations in the individual records corresponding to the subtidal dunes are clearly distinguished. The variations in the radar derived transect appear to follow a smoothed version of those in the survey as might be expected from this type of analysis.
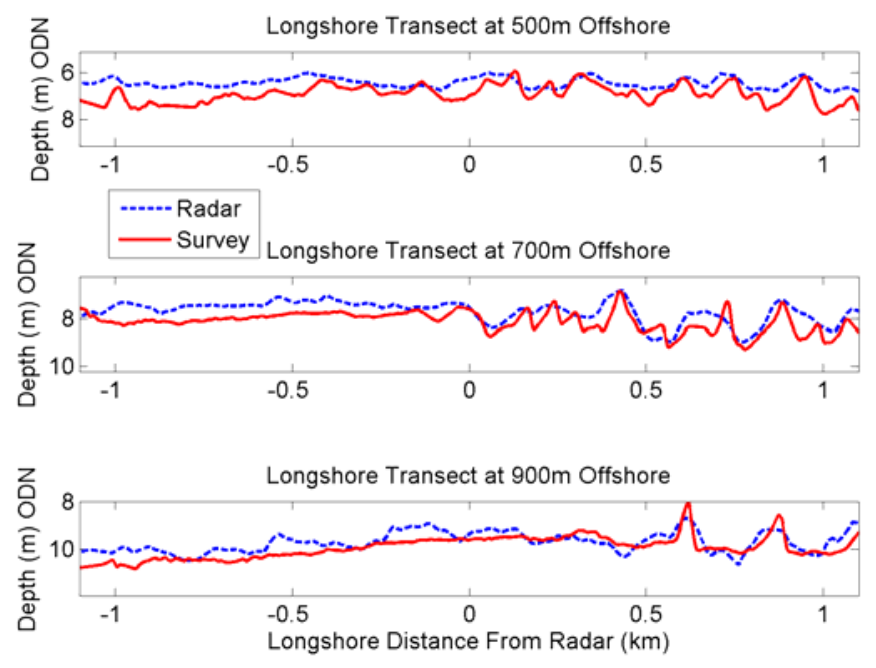

Figure 4. A comparison of longshore bathymetry transects derived from the radar (Blue dotted line) and survey data (Red solid line) 
This presents the possibility of tracking the migration of such dune features over extended periods of time, and early results indicate that the features maintain coherence and can be seen to migrate in the positive ' $x$ ' direction. This corresponds to a long shore migration to the south east as expected from the prevailing long shore drift and residual currents for that area. This net migration of dune features in water depths of $6-10 \mathrm{~m}$ represents a significant transport pathway for sediment on that part of the coast, and one that has previously not been accounted for.

Further work will aim to derive the flux of sediment contained within these migrating dune features, allowing their relative importance to the sediment budget to be assessed compared with more conventional estimates of long shore drift in the intertidal zone.

\section{RESULTS - CURRENTS}

Current measurements derived from the radar compared favorably with depth mean currents measured using an Acoustic Doppler Current Profiler located close to the northernmost breakwater. A comparison of the long shore component of the depth mean ADCP record with the corresponding radar derived long shore current is shown in Figure 5. These data show that during the peak of the wave event in the first half of the plot, the wave driven near shore currents overwhelmed the normal tidal reversal. Then as the storm subsided the normal tidal reversal returned in the latter half of the plot. There is a consistent residual flow to the south east (a negative bias on the plot) for the whole period, probably driven by the waves approaching from the north.

A second radar derived time series of currents is shown in Figure 6 together with the same ADCP record. This radar derived time series is taken from a point $1 \mathrm{~km}$ offshore and directly seawards of the radar position. The data shows that at that position the tidal currents were able to reverse even at the height of the storm and there is far less evidence of a residual flow to the south east. This suggests that the wave driven 'jet' was confined close to the shore.

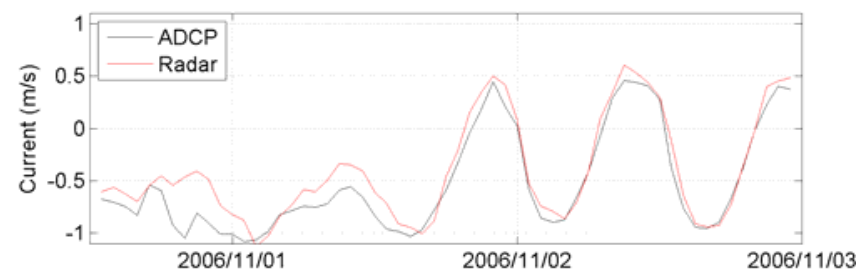

Figure 5. Comparison of depth mean long shore currents measured by an ADCP close to the northernmost breakwater (black) compared with radar derived longshore currents at the same location (red).
The radar derived currents in Figure 6 also hint at a slight phase shift compared with those at the ADCP position at the northernmost breakwater, which would be consistent with the propagation direction of the tide. This suggests that it might be possible to derive maps of the tidal phase at high resolution from such data, and this will also be investigated in further work.

\section{ACKNOWLEDGEMENTS}

Thanks are due to the UK Engineering and Physical Sciences Research Council and Natural Environment Research Council for funding and to the Palling Volunteer Rescue Service for the radar site.

\section{REFERENCES}

[1] Dolphin, T.J., Taylor, J.A., Vincent, C.E., Bacon, J.B., Pan, S., O’Conner, B.A., "Storm-scale effects of shore-parallel breakwaters on beaches in a tidal setting (LEACOAST)", Proceedings of the 29th International Conference on Coastal Engineering, Lisbon (Portugal), Vol. 3 pp 2849-2861, 19-24 September 2004.

[2] Hedges, T.S., "An empirical modification to linear wave theory”. Proc. Inst. Civ. Eng., 61, 575-579, 1976.

[3] Booij, N., "Gravity waves on water with non-uniform depth and current”. Rep. No.81-1, Dept. Civ. Eng., Delft university of Technology, 1981.

[4] Young, I.R., Rosenthal, W. and Ziemer, F., “A threedimensional analysis of marine radar images for the determination of ocean wave directionality and surface currents”. J. Geophysical Research, 90, C1, 1049-1059, 1985.

[5] Bell, P.S., Williams, J.J., Clark, S., Morris, B.D., Vila-Concejo, A., "Nested radar systems for remote coastal observations", Journal of Coastal Research, SI39 (Proceedings of the $8^{\text {th }}$ International Coastal Symposium, Itajaí, SC (Brazil)), pp 483-487, 14-19 March 2004.

[6] Bell, P.S., "Remote bathymetry and current mapping around shore-parallel breakwaters", Proceedings of 33rd International Association of Hydraulic Engineering \& Research (IAHR) Biennial Congress, Vancouver, Canada, August 9-14, 2009.

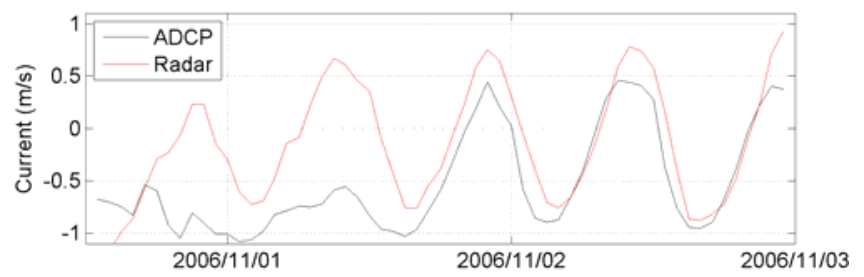

Figure 6. Comparison of depth mean ADCP longshore current at the northernmost breakwater (black) with radar derived longshore current $1 \mathrm{~km}$ directly offshore of the radar (red). 